\title{
Obstetric Emergencies: Feto-maternal Outcome at a Teaching Hospital
}

\author{
Saha R, Gautam P
}

Department of Obstetrics and Gynaecology, Kathmandu Medical College Teaching Hospital, Kathmandu, Nepal.

\begin{abstract}
Aims: This study was done to know the pattern of obstetric emergencies and its influence on maternal and fetal outcome.
Methods: A descriptive study was carried out in the department of obstetrics and gynecology at Kathmandu Medical College Teaching Hospital from 1st June 2013 to $31^{\text {st }}$ May 2014. Cases were categorized as early pregnancy emergencies (ruptured ectopic pregnancy, complications of abortion), ante-partum emergencies and intra-partum emergencies (antepartum haemorrhage, preeclampsia, eclampsia, preterm prelabor rupture of membranes, rupture uterus), post-partum emergencies (postpartum haemorrhage, retained placenta, placenta accreta, uterine inversion), puerperal emergencies (postpartum sepsis), fetal emergencies (cord prolapse, shoulder dystocia). Outcome noted were type of emergency, obstetric intervention done, maternal and perinatal morbidity and mortality.
\end{abstract}

Results: A total of 80 (4.45\%) obstetric emergencies occurred among 1796 deliveries . The most common obstetric emergencies were obstetric hemorrhage $(62.5 \%)$, severe preeclampsia $(23.5 \%)$ and preterm prelabor rupture of membranes $(10 \%)$. The obstetric interventions done were cesarean section (43.75\%), exploratory laparotomy (33.75\%) and blood transfusion (40\%). Obstetric emergencies were responsible for $66.6 \%$ of total maternal death and $24.56 \%$ of total perinatal death.

Conclusions: In spite of best efforts, some obstetric emergencies do occur. Obstetric hemorrhage and severe preeclampsia are the frequent obstetric emergencies. Cesarean section, exploratory laparotomy and blood transfusion were the commonly performed interventions. A better outcome can be achieved by national policy of promoting utilization of antenatal care, institutional deliveries, skilled birth attendance at delivery, liberal blood transfusion and regular training of doctors and nurses.

Keywords: fetal outcome, maternal outcome, obstetric emergency, obstetric haemorrhage, severe preeclampsia.

\section{INTRODUCTION}

No specialty of medicine is more inundated with emergencies than obstetrics. ${ }^{1}$ While most childbirth related complication allows time for proper management, a few present as obstetric emergencies where successful outcome depends on prompt action and systematic rapid management..$^{1-4}$

Obstetric emergencies are defined as situations of serious and often dangerous nature, developing suddenly and unexpectedly and demanding immediate attention in order to save life..$^{1-4}$ These emergencies are not only encountered in perinatal period as post-partum hemorrhage, ruptured uterus, retained placenta, etc. but also in early pregnancy

\section{CORRESPONDENCE}

Dr Rachana Saha

Department of Obstetrics and Gynecology,

Kathmandu Medical College Teaching Hospital, Kathmandu.

Phone: +977-9841241296

Email: rachana_saha@yahoo.com as ruptured ectopic, complications of abortion, antepartum haemorrhage and ante-partum eclampsia all being equally fatal. ${ }^{1-4}$ Though measures to reduce maternal mortality have decreased the rate but still the rates are high in developing countries according to WHO. ${ }^{5}$ Plenty of studies on maternal mortality have been done but none on obstetric emergencies and its effect on maternal and perinatal mortality in Nepal. This study was therefore conducted to know the pattern of obstetric emergencies and its maternal and fetal outcome.

\section{METHODS}

A retrospective with prospective follow up study was carried out in the department of obstetrics and gynecology of Kathmandu Medical college Teaching Hospital (KMCTH) from1st June 2013 to $31^{\text {st }}$ May 2014. Cases were included in the study if they had ruptured ectopic pregnancy, ante-partum hemorrhage, pre-eclampsia/eclampsia, preterm prelabor rupture of membranes, rupture of uterus, inversion of uterus, 
cord prolapse, retained placenta, placenta accreta, shoulder dystocia, post-partum hemorrhage, postpartum sepsis. Cases were identified from multiple sources from maternity computer databases, labor ward, postnatal ward and medical record section. Categorization was done as early pregnancy emergencies, ante-partum and intra-partum emergencies, post-partum emergencies and fetal emergencies. Informations were obtained regarding maternal age, parity, occupation, booking status, type of emergency, emergency obstetric intervention done, maternal and perinatal morbidity and mortality. The quantitative variables are presented frequency, percentage and means SD values.

\section{RESULTS}

A total of 80 obstetric emergencies occurred among 1796 deliveries during the study period. Most of the cases were primi and had antenatal care in KMCTH (table 1). The most frequent obstetric emergency was hemorrhage $(50 \%)$ of which ectopic pregnancy was the most common cause $(33.75 \%)$ \{ Table 2$\}$. Rare ones were cord prolapse, puerperal pyrexia and amniotic fluid embolism. Most of the emergency took place in antepartum period (Table 2). Most frequent emergency obstetric intervention was caesarean section (43.75\%) followed by exploratory laparotomy $(33.75 \%)$ and blood transfusion (Table 3$)$. There were 2 maternal deaths resulting from obstetric emergency contributing to $66.6 \%$ of total maternal death. There were 14 perinatal deaths of total 57 perinatal deaths contributing to $24.56 \%$ (Table 3 ) of total perinatal mortality.

Table 1. Maternal characteristics $(n=80)$.

\begin{tabular}{lll}
\hline $\begin{array}{l}\text { Maternal } \\
\text { Characteristics }\end{array}$ & Number & Percentage \\
\hline $\begin{array}{l}\text { Parity } \\
\text { Primigravida }\end{array}$ & 54 & \\
Multiparra & 26 & 22.5 \\
ANC & & \\
KMCTH & 55 & 68.7 \\
Within Kathmadu & 16 & 20.0 \\
Referred Cases & 09 & 11.3 \\
Total & 80 & 100 \\
Period of Gestation & Mean (SD) days & \\
Ectopic Pregnacy & $49.33(12.5)$ & \\
Other Pregnancy & $260.8(35.9)$ & \\
\hline
\end{tabular}

Table 2. Obstetrics Emergencies and its frequency $(n=80)$.

\begin{tabular}{lll}
\hline $\begin{array}{l}\text { Obstetric } \\
\text { emergencies }\end{array}$ & Number & Percentage \\
\hline $\begin{array}{l}\text { Early pregnancy and } \\
\text { antepartum } \\
\text { emergency }\end{array}$ & & \\
Obstetric hemorrhage & 50 & 62.5 \\
Ectopic pregnancies & 27 & 33.75 \\
APH & 14 & 17.5 \\
Placenta previa & 10 & 12.5 \\
Abruptio placentae & 4 & 5 \\
PPH & 9 & 11.25 \\
Severe pre-eclampsia & & \\
and eclampsia & 19 & 23.75 \\
PPROM & 8 & 10 \\
Amniotic fluid embolism & 1 & 1.2 \\
Puerperal pyrexia & 1 & 1.2 \\
Cord prolapse & 1 & 1.2 \\
\hline *APH= Ante Partum Hemorrhage *PH= Post Partum Hemorrhage*PPROM= \\
Preterm Prelabor Rupture of Membranes
\end{tabular}

Table 3. Emergency obstetric intervention and outcome $(n=80)$.

\begin{tabular}{lll}
\hline Type of Intervention & Number & Percentage \\
Vaginal delivery & 10 & 12.5 \\
Vacuum delivery & 4 & 5 \\
Cesarean section & 35 & 43.7 \\
Exploratry lapratomy & 27 & 33.7 \\
for ectopic pregnancy & & \\
ICU Admission & 16 & 20 \\
Yes & 64 & 80 \\
No & 32 & 40 \\
Blood transfusion required & 22 & \\
Ectopic pregnancies & 4 & \\
APH & 6 & \\
PPH & & \\
Outcomes & 78 & 2.5 \\
Discharged cases & 2 & 17.5 \\
Maternal Death & 14 & \\
Perinatal mortality & & \\
\hline
\end{tabular}

\section{DISCUSSION}

Safe motherhood programme of Nepal has focused on improving the availability, quality and utilization of emergency obstetric care in the district hospitals so as to address the needs of the estimated $15 \%$ of pregnancies likely to develop serious complications. ${ }^{6}$ 
Programme also makes availability of skilled attendance at every delivery, safe blood transfusion, free delivery scheme, financing transport to the health facility and also has made available safe abortion services reducing the abortion related death and complications. ${ }^{6}$

This study showed that obstetric emergency is frequent with incidence of $4.45 \%$ of all deliveries. This high rate could be due to inclusion of pre-term pre-labour rupture of membranes in this study. Most of the studies reviewed focused on inclusion of specific or severe maternal morbidity. ${ }^{5,7-11}$ Maternal mortality is used internationally as measure of the quality of obstetric intervention, although is now rare in the developed world. ${ }^{7}$ Severe maternal morbidity have been used as a alternative measure.,11 Severe obstetric morbidity was defined clinically to be severe preeclampsia,severe obstetric hemorrhage and sepsis. ${ }^{7-8}$ Overall incidence is $1.2 \%$ of all deliveries. $^{7}$ Two third cases are related to severe hemorrhage, one third to severe preeclampsia. ${ }^{7-11}$ This study also concluded that obstetric hemorrhage was the most frequent leading obstetric emergency of which hemorrhage due to ectopic pregnancy was the leading cause. Severe preeclampsia was the second most common cause encountered. Most of the studies also found these two causes as obstetric emergency, ${ }^{3,4}$ severe obstetric morbidity, ${ }^{7,8}$ or indication to ICU admission. ${ }^{11}$ The incidence of post-partum hemorrhage is comparatively less and this could be due to practice of active managementof third stage of labor with oxytocin. In frequency of prevalence, preterm prelabor rupture of membrane was rated third. Preterm labor and delivery though is $10 \%$ but results in $85 \%$ of perinatal mortality. ${ }^{1}$ No health care problem costs more than this. ${ }^{1}$ Again none of the studies has included preterm prelabor rupture of membranes. Preterm labor requires arrest of labor, administration of steroids, and transfer of the patient to better equipped neonatal centre or delivery of the baby to well facilitated centre. This study does not have prolonged or obstructed labor or uterus rupture as obstetric emergency and this could be due to compulsory practice of partograph and patients preference of doing elective caesarean section in cases of post caesarean pregnancy. The hospital also practices principles of infection prevention and routine use of antibiotics after delivery, so cases of severe sepsis was infrequent.
Most of the cases were admitted during ante-partum period. Most of the patients had caesarean section as obstetric emergency intervention. Exploratory laparotomy was the second frequent obstetric emergency intervention done but none of the studies has included ectopic pregnancy as obstetric emergency. Only 20\% (16) had ICU admission for mainly severe preeclampsia and for haemodynamic instability. This was in conjunction with similar study done by Saha et al. ${ }^{11}$ Blood transfusion was required in 32 cases mostly for obstetric haemorrhage. The hospital provides blood transfusion services and relatives of patients are requested to donate or provide donors when blood transfusion is required similar to Nigerian study. ${ }^{4}$ All the cases of severe preeclampsia had successful outcome due to practice of magnesium sulphate. Most of patient had successful outcome with maternal mortality resulting in two $(66.6 \%)$ of total three cases. Two cases of maternal death resulted from obstetric hemorrhage and one death resulted from indirect cause. Obstetric hemorrhage has been the most common cause of maternal death world wide. $^{3-5,7-11}$

Overall there were $14(17.5 \%)$ perinatal death resulting from obstetric emergency from a total of 57 cases accounting for $24.56 \%$ of all perinatal mortality which is quite low when compared to Nigerian study ${ }^{4}$ of $83 \%, 42.3 \%$ by Singh et al. ${ }^{3}$ A better outcome of obstetric emergency can be achieved by effective management of obstetric emergency, promoting institutional deliveries, providing skill attendance at deliveries, providing safe freely availability of blood transfusion, government policy and regular training of doctors and nurses on this subject. ${ }^{3,4}$

\section{CONCLUSIONS}

In spite of best efforts and national policies obstetric emergencies do occur. Some occur more frequently and some rarely. The most frequent are obstetric hemorrhage and severe preeclampsia followed by preterm prelabor rupture of membranes and rare ones are amniotic fluid embolism, cord prolapse. Optimal outcome can be achieved by availability of emergency obstetric care at the facility, maximum utilization of antenatal care, skilled birth attendance at labor, availability of blood transfusion facilities, and mother friendly national policy. 


\section{DISCLOSURE}

The authors report no conflicts of interest in this work.

No violation of human rights and safety.

Funding: Nil

\section{REFERENCES}

1. Avery DM. Obstetric Emergencies. AJCM. 2009;6(2):42-7.

2. Campbell S, Lee C. Obstetric emergencies. In Campbell S, Lee C, editors. Obstetrics by ten teachers. $17^{\text {th }}$ ed. Arnold Publishers: London; 2000.p303-17.

3. Singh A, Nandi L. Obstetric Emergencies: role of obstetric drill for a better maternal outcome. J Obstet Gynecol of India. 2012; 62(3):291-6.

4. Lamina MA, Oladapo OT.Maternal and Fetal Outcome of Obstetric Emergencies in a tertiary Health Instituion in Southwestern Nigeria. ISRN Obstet Gynecol. 2011;2011:160932.

5. WHO, UNICEF, UNFPA. Maternal mortality in 2005. Estimates developed by WHO, UNICEF, and UNFPA; 2005 .

6. Barker CE, Bird CE, Pradhan A. Support to the Safe Motherhood Programme in Nepal: an integrated approach. Reprod Health Matters. 2001;15(30):81-90.

7. Waterson M, Bewely S, Wolf C.Incidence and predictors of severe obstetric morbidity: case- control study. BMJ. 2001;322:1089-94.

8. Zhang WH, Alexander S, Bouvier-Colle MH, Macfarlane A. Incidence of severe pre-eclampsia, postpartum haemorrhage and sepsis as surrogate marker for severe maternal morbidity in a European -based study: MOMS survey. BJOG. 2005;112(1):89-96.

9. Bang RA, Bang AT, Reddy MH, Deshmukh MD, Baitule SB, Fillipi V. Maternal morbidity during labour and puerperium in rural homes and the need for medical attention: a prospective observational study in Gadchiroli, India. BJOG. 2004;111(3):231-8.

10. Gupta S, Naithani U, Doshi V, Bhargava V, Vijay BS Obsteric critical care: A Prospective analysis of clinical characterstics, predicatability and fetomaternal outcomein a new-dedicated obstetric intensive care unit. Indian $\mathrm{J}$ Anaesth. 2011;55(2):146-53

11. Saha R, Shakya A. Study of obstetric patients admitted to Intensive Care unit at Kathmandu Medical College Teaching Hospital. JKMC. 2013;2(6):196-200. 